\title{
Trilateral Retinoblastoma
}

\section{: A Case Report}

\begin{abstract}
Trilateral retinoblastoma is a rare, but well recognized syndrome. These tumors usually occur in the pineal, parasellar, or suprasellar regions several years after successful management of ocular retinoblastomas without evidence of direct extension or distant metastasis. Here we report a case of trilateral retinoblastoma presenting initially with a sellar tumor and with concurrent unilateral retinoblastoma. The patient was a 5-month-old baby girl showing poor eye contact and nystagmus for several days. She had no family history of retinoblastoma. Brain MRI revealed a midline suprasellar tumor without evidence of cerebrospinal fluid seeding or extracranial metastasis. A pathologic diagnosis of retinoblastoma was made for her brain tumor, and a small, intraocular retinoblastoma was detected in the left eye by thorough examination of the fundus. If a retinoblastoma occurs in the midline of the brain, including the pineal and sellar regions, a careful screening to detect any additional retinal tumors should be performed. Moreover, since these tumors are often hereditary and harbor a worse prognosis, the diagnosis has implications for genetic counseling. This is the first report on a case of trilateral retinoblastoma in Korea presented with a sellar mass.
\end{abstract}

Key Words : Retina; Sella Turcica; Neoplasms; Retinoblastoma

\author{
Eun Yoon Cho, Yeon-Lim Suh, \\ Hyung-Jin Shin*
}

Departments of Diagnostic Pathology and
Neurosurgery*, Samsung Medical Center,
Sungkyunkwan University School of Medicine,
Seoul, Korea
Received : 19 December 2000
Accepted : 2 April 2001
Address for correspondence
Yeon-Lim Suh, M.D.
Department of Diagnostic Pathology, Samsung
Medical Center, Sungkyunkwan University School
of Medicine, 50 llwon-dong, Kangnam-gu, Seoul
135-710, Korea
Tel : +82.2-3410-2800, Fax : +82.2-3410-0025
E-mail : ylsuh@smc.samsung.co.kr

Departments of Diagnostic Pathology and Neurosurgery*, Samsung Medical Center Sungkyunkwan University School of Medicine Seoul, Korea

Received : 19 December 2000 Accepted : 2 April 2001
Address for correspondence
Yeon-Lim Suh, M.D.
Medical Center, Sungkyunkwan University School 135-710, Korea
E-mail : ylsuh@smc.samsung.co.kr

Retinoblastoma (RB) is the most common intraocular malignancy found in children. It is caused by the inactivation of both copies of a tumor suppressor gene (R bl), which participates in the control of cell cycling (1-3). Approximately onethird of these tumors are bilateral and is associated with germinal mutations. All bilateral tumors and one tenth of unilateral tumors are caused by a germline mutation inherited as an autosomal dominant trait $(4,5)$. This hereditary predisposition to retinoblastoma is caused by mutant alleles occurring at the q14 band of chromosome 13 (6). The association of bilateral RB with ectopic midline intracranial tumors, termed "trilateral" retinoblastoma (TRB), is a well recognized but uncommon syndrome. The association of ocular RB with brain tumors was first reported in 1971 (7). The intracranial tumor arises most often in the pineal region but can al so be a suprasellar or parasellar tumor, and is considered to be an isol ated independent primary focus without evidence of retinal disease. This is the first reported case of TRB presented with a sellar and suprasellar tumor in Korea.

\section{CASE REPORT}

A 5-month-old femaleinfant presented with poor eye con- tact and nystagmusfor several days. Brain MRI reveal ed a reatively well circumscribed, lobulated mass, measuring $7.5 \times$ $5.7 \mathrm{~cm}$ in the sella and suprasella regions (Fig. 1). This mass showed heterogeneous signal intensity and variable contrast enhancement in both T1-weighted and T2-weighted images (Fig. 2). There was permeative growth al ong the optic gyruS, but no ocular lesion was found in the preoperative brain MRI. The brain tumor was partially resected. Pathologic diagnosis of intracranial RB was made. Subsequently, with a suspicion of TRB, ophthal moscopic examination was performed. It reveal ed an intraocular whitish subretinal mass, twice the diameter of a disc on the left eye. N o histologic confirmation was made for the ocular lesion. She did not have a family his tory of RB. Postoperatively, the patient received chemotherapy with cytoxan, vancomycin, and adriamycin. Follow-up CT of the brain revealed shrinkage of the residual mass in response to chemotherapy and there was no evidence of meta stasis or leptomeningeal spreading. She died of sepsis 6 months thereafter.

Pathologic examination of the removed brain tumor disclosed a dense proliferation of small, round, and blue cells with a high nucleus: cytoplasmic ratio, hyperchromatic nuclè and some mitoses. M any Flexner-W intersteiner rosettes and $\mathrm{H}$ omer W right rosettes were observed (Fig. 3). Cal cifications and necroses were also frequently seen. Thetumor showed dif- 


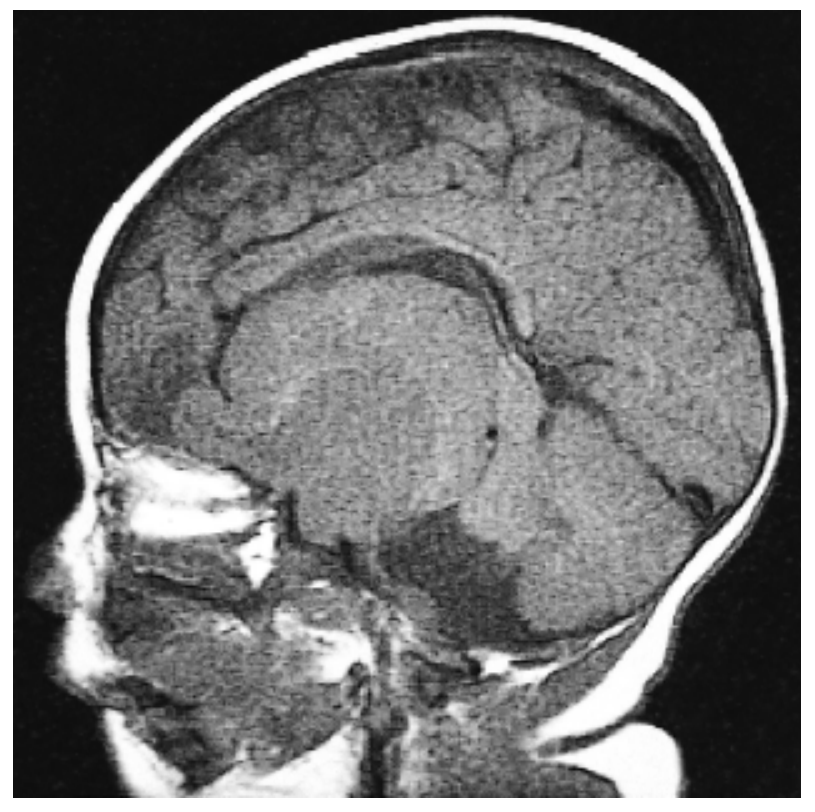

Fig. 1. Sagittal view of T1-weighted MRI of the brain. Note a large, relatively well circumscribed suprasellar mass extending posteriorly, displacing the brain stem, as well as into the anterior cranial fossa.

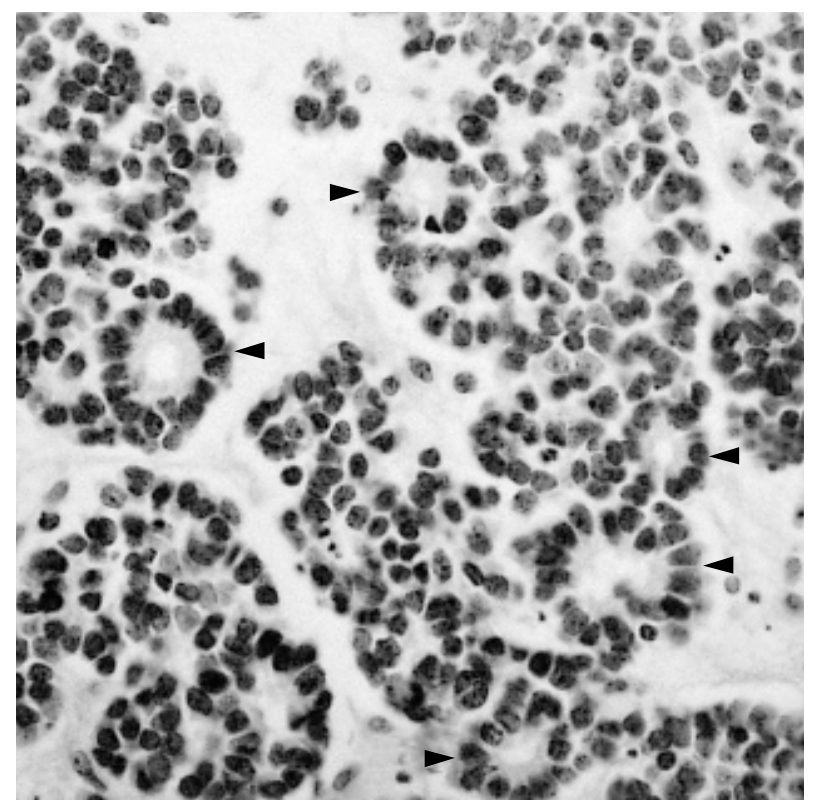

Fig. 3. Histopathologic examination of the intracranial tumor demonstrates typical features of retinoblastoma. The small round tumor cells represent many Flexner-Wintersteiner rosettes (arrowheads) with mitotic figures $(H \& E, \times 200)$.

fuse immunoreactivity for synaptophysin (Fig. 4). Immunostainings for S-100, GFAP, EMA, vimentin, CD99, and colla gen IV were all negative. These findings were consistent with the diagnosis of intracranial RB.

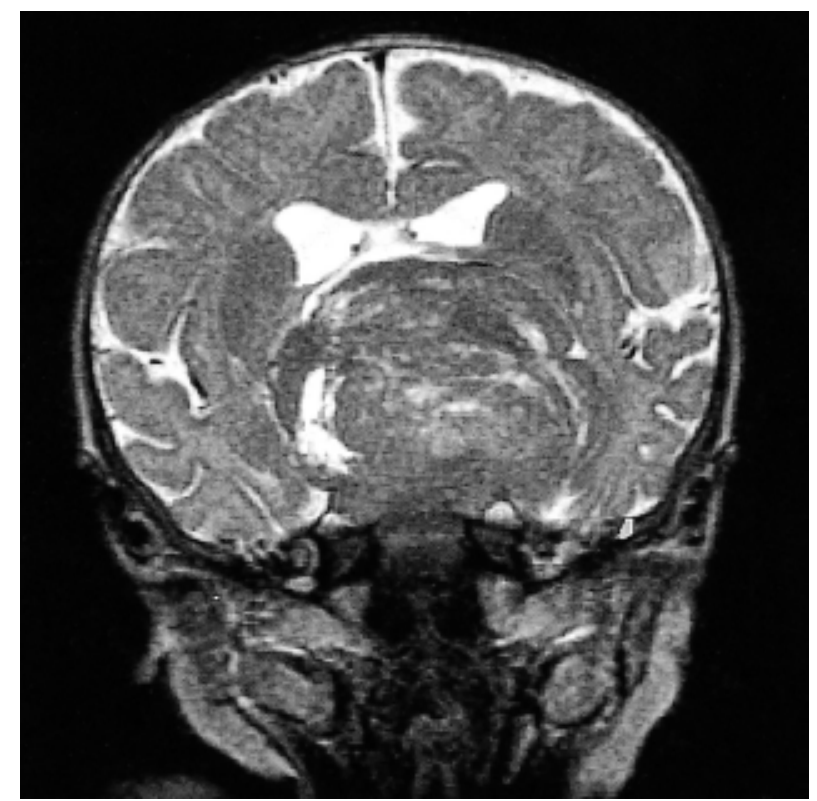

Fig. 2. Coronal view of contrast-enhanced T2-weighted MRI of the brain. Slightly heterogeneous enhancement of the suprasellar mass is noted.

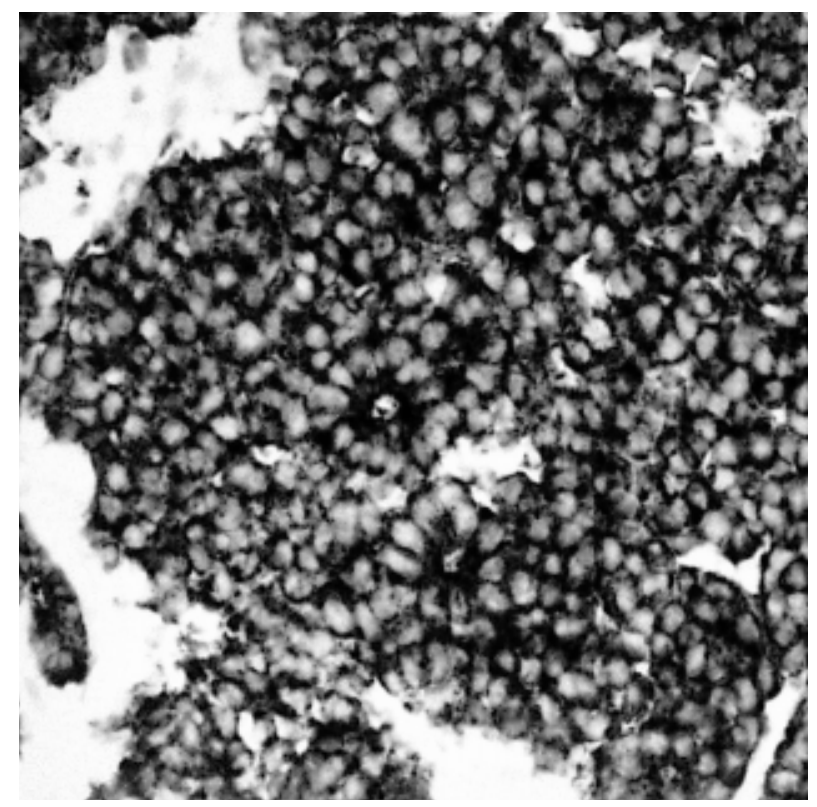

Fig. 4. Note the strong immunoreactivity for neuronal marker (synaptophysin) in the cytoplasms of tumor cells $(\times 200)$.

\section{DISCUSSION}

TRB is a well-recognized syndrome that is characterized by unilateral or bilateral hereditary RB in association with a morphologically similar intracranial neoplasm localized in the 
pineal gland or the sella or suprasella regions. This case demonstrated TRB with a sellar and suprasellar mass as well as unilateral retinoblastoma. TRB with unilateral RB has also been described as a forme fruste of TRB (8).

The intracranial tumor of TRB arises most often in the pineal gland but can occur in the suprasellar or parasellar regions as well. The association between suprasellar tumor and ocular RBs is referred to as "sellar" TRB, wheress "pined" TRB is refers to pineal tumor associated with ocular RBs. Bejjani et al. reported a case of suprasellar mass with intraocular RB, which showed nearly same presentation as the present case. The intracranial mass of sellar TRB tends to be the initial presenting tumor and is diagnosed at a younger age than the "pineal" variant since they more readily develop symptoms of increased intracranial pressure than pineal variants. It has a tendency to occur more frequently in females and is associated more often with unilateral ocular lesions, as is the case in our patient (9). Although the patients with suprasellar TRB are diagnosed earlier than those with pineal TRB, their prognosis remains poor and they usually die of metastatic disease or postoperative complications within 10 months from the diagnosis (10). Three cases of unilateral RB and sellar tumor without family history has been reported in English literature since 1977 (9, 11, 12).

Ocular disease in TRB presents much earlier than that in classic RB with a usual latent period between the diagnosis of ocular disease and the intracranial lesion $(13,14)$. As for our patient, ocular tumor was not discovered in the preoperative brain MRI, but was detected postoperatively by the fundoscopic examination. The ocular mass in this patient might be a concurrent lesion. According to several studies, the mean survival in patients with TRB varies from 1 to 28 months after diagnosis of the intracranial lesion and the disease is almost uniformly fatal with deaths most commonly due to cerebrospinal metastases $(13,15)$. In contrast, the 5 yr survival of unilateral ocular RB following adequate treatment is over $90 \%$ and slightly less in cases with bilateral lesions.

In TRB, the retinal tumor is usually small and thereis often no optic nerve involvement, and both of these factors argue against cerebral metastasis $(11,16)$. The sellar mass of our patient can not be considered as a metastasis from the retinal lesion because there was no involvement of the optic nerve or uveal tract, or extraocular extension, as shown by ophthal mic examination as well as on MRI.

The ocular RB can extend to the brain by the optic nerve invasion or by spreading through the cerebrospinal fluid. Typically, cerebra metastasis represents multiple lesions with similar imaging characteristics, and the midlinelocation is uncharacteristic of the metastatic lesions: they are a so often associated with skull vault, long bone, and pulmonary metastases. The present case showed no evidence of cerebrospinal fluid spreading or hematogenous metastasis.

In addition, metastatic $R B s$ are morphologically different from primary intracranial RB. They are characterized by undifferentiated small round cells without Flexner-W intersteiner rosettes resembling neuroblastoma, whereas the primary lesions are morphological ly similar to ocular RB. The histologic findings of this case were similar to those seen in ocular RB.

It is less likely that this patient may have an ocular metastasis from intracranial retinoblastoma because orbital meta static tumors in children are most often of embryonal or undifferentiated type, such as neuroblastoma, Wilms'tumor, and Ewing sarcoma. And orbital metastasis of the intracra nial tumors is extremely rare except medulloblastoma.

M ost of the theories on the origin of TRB are based on K nudson's proposal, suggesting that two genetic events ("hits") take place, triggering the development of hereditary RB. The first mutation is inherited and the second muta tion, which takes place in the retina, is acquired during life (17). Bader et al. believed that these two genetic "hits" are responsible for the occurrence of intracranial $R B$, and originally stated that the "second primary" tumors are found in the socalled "third eye", the pineal gland (18). There are two theories that may explain the occurrence of a suprasellar variant: Susceptibility to RB gene mutation may be shared by additional cells such as germinal matrix cells in CN S, since the optic primordia develop from the diencephal on. The other hypothesis for suprasellar TRB is the occurrence of tumors from ectopic photoreceptor cells in the sellar area. This theory is supported by the reports on ectopic retinal epithelium in an intracranial portion of the optic nerve (11, 19).

Present case has a possibility of congenital intracranial tumor due to early presentation of 5 months.

The risk of occurrence of $R B$ in siblings of patients with TRB varies between 1 and $7 \%$, depending on the presence of a family history $(13,14,20)$. Although we must consider lag time bias, which may be attributable to the time of scre ening or the intractability of this tumor, a screening for intracranial disease can be beneficial for children with bilateral and hereditary RB. The intraocular lesion in our patient might have been missed, had it not been for the detailed examination of the ocular fundus since she had no family history and the lesion was very small. Careful retinal screening of patients with 'sellar' or other non-pineal RB may uncover patients with TRB. Since TRB is often hereditary, the diagnosis has implications for genetic counseling, as siblings of the patient may al so have the disease. The patie nts may initially present with a suprasellar tumor or concurrent intraocular RB with suprasellar tumor. The importance of meticulous search for retinal lesions in children with parasellar RB is stressed to assure the diagnosis of sporadic heritable forms of 'sellar' TRB and referral for genetic counseling. 


\section{REFERENCES}

1. Mayol X, Grana X. pRB, p107 and p130 as transcriptional regulators: role in cell growth and differentiation. Prog Cell Cycle Res 1997; 3: 157-69.

2. Sellers WR, Kaelin WG Jr. Role of the retinoblastoma protein in the pathogenesis of human cancer. J Clin Oncol 1997; 15: 3301-12.

3. Herwig S, Strauss M. The retinoblastoma protein: a master regulator of cell cycle, differentiation and apoptosis. Eur J Biochem 1997; 246: 581-601.

4. Gallie BL, Dunn JM, Hamel PA, Muncaster M, Cohen BL, Phillips RA. How do retinoblastoma tumours form? Eye 1992; 6: 226-31.

5. Draper GJ, Sanders BM, Brownbill PA, Hawkins MM. Patterns of risk of hereditary retinoblastoma and applications to genetic counseling. Br J Cancer 1992; 66: 211-9.

6. Sparkes RS, Murphree AL, Lingua RW, Sparkes MC, Field LL, Funderburk SJ, Benedict WF. Gene for hereditary retinoblastoma assigned to human chromosome 13 by linkage to esterase D. Science 1983; 219: 971-3.

7. Jensen RD, Miller RW. Retinoblastoma: epidemiologic characteristics. N Engl J Med 1971; 285: 307-11.

8. Whittle IR, McClellan K, Martin FJ, Johnston IH. Concurrent pineoblastoma and unilateral retinoblastoma: a forme fruste of trilateral retinoblastoma? Neurosurgery 1985; 17: 500-5.

9. Bejjani GK, Donahue DJ, Selby D, Cogen PH, Packer R. Association of a suprasellar mass and intraocular retinoblastoma: a variant of pineal trilateral retinoblastoma? Pediatr Neurosurg 1996; 25: $269-75$.
10. Blash L, McCormick B, Abramson D, Ellsworth R. Trilateral retinoblastoma-incidence and outcome: a decade of experience. Int J Radiat Oncol Biol Phys 1994; 29: 729-33.

11. Jakobiec FA, Tso MO, Zimmerman LE, Danis P. Retinoblastoma and intracranial malignancy. Cancer 1977; 39: 2048-58.

12. Skulski M, Egelhoff JC, Kollias SS, Mazewski C, Ball WS. Trilateral retinoblastoma with suprasellar involvement. Neuroradiology 1997; 39: 41-3.

13. Pesin SR, Shields JA. Seven cases of trilateral retinoblastoma. Am J Ophthalmol 1989; 107: 121-6.

14. De Potter P, Shields CL, Shields JA. Clinical variations of trilateral retinoblastoma: a report of 13 cases. J Pediatr Ophthalmol Strabismus 1994; 31: 26-31.

15. Bader JL, Meadows AT, Zimmerman LE, Rorke LB, Voute PA, Champion LA, Miller RW. Bilateral retinoblastoma with ectopic intracranial retinoblastoma: trilateral retinoblastoma. Cancer Genet Cytogenet 1982; 5: 203-13.

16. Bader JL, Miller RW, Meadows AT, Zimmerman LE, Champion LA, Voute PA. Trilateral retinoblastoma. Lancet 1980; 2: 582-3.

17. Knudson AG Jr. Mutation and cancer: statistical study of retinoblastoma. Proc Natl Acad Sci USA 1971; 68: 820-3.

18. Wurtman RJ, Moskowitz MA. The pineal organ (first of two parts). N Engl J Med 1977; 296: 1329-33.

19. Torczynski E, Jacobiec FA, Johnston MC, Font RL, Madewell JA. Synophthalmia and cyclopia: a histopathologic, radiographic, and organogenetic analysis. Doc Ophthalmol 1977; 44: 311-78.

20. Kingston JE, Plowman PN, Hungerford JL. Ectopic intracranial retinoblastoma in childhood. Br J Ophthalmol 1985; 69: 742-8. 